\title{
Multiple Criteria Decision Making
}

From Early History to the 21st Century 


\title{
Multiple Criteria Decision Making From Early History to the 21st Century
}

\author{
Murat Köksalan \\ Middle East Technical University, Turkey \\ Jyrki Wallenius \\ Aalto University, Finland \\ Stanley Zionts \\ SUNY Buffalo, USA
}

\section{No World Scientific}


This page is intentionally left blank 


\section{Published by}

World Scientific Publishing Co. Pte. Ltd.

5 Toh Tuck Link, Singapore 596224

USA office: 27 Warren Street, Suite 401-402, Hackensack, NJ 07601

UK office: 57 Shelton Street, Covent Garden, London WC2H 9HE

\section{British Library Cataloguing-in-Publication Data}

A catalogue record for this book is available from the British Library.

\section{MULTIPLE CRITERIA DECISION MAKING \\ From Early History to the 21st Century}

Copyright (C) 2011 by World Scientific Publishing Co. Pte. Ltd.

All rights reserved. This book, or parts thereof, may not be reproduced in any form or by any means, electronic or mechanical, including photocopying, recording or any information storage and retrieval system now known or to be invented, without written permission from the Publisher.

For photocopying of material in this volume, please pay a copying fee through the Copyright Clearance Center, Inc., 222 Rosewood Drive, Danvers, MA 01923, USA. In this case permission to photocopy is not required from the publisher.

ISBN-13 978-981-4335-58-4

ISBN-10 981-4335-58-4

Typeset by Stallion Press

Email: enquiries@stallionpress.com

Printed in Singapore. 


\section{Contents}

Preface vii

Chapter 1 The Early History of MCDM 1

Chapter 2 MCDM Developments in the 1970s 17

Chapter 3 MCDM Developments in the 1980s 31

Chapter 4 MCDM Developments in the 1990s and Beyond 43

Chapter 5 MCDM Conferences 63

$\begin{array}{lll}\text { Chapter } 6 & \text { MCDM Society Traditions } & 89\end{array}$

$\begin{array}{lll}\text { Chapter } 7 & \text { Awards and Presidents } & 93\end{array}$

Chapter 8 Biographies of Leading MCDM Scholars 95

$\begin{array}{lll}\text { Chapter } 9 \text { Conclusion } & 157\end{array}$

$\begin{array}{ll}\text { References } & 161\end{array}$

$\begin{array}{ll}\text { Subject Index } & 185\end{array}$

Name Index 191 
This page is intentionally left blank 


\section{Preface}

What led to the writing of this book?

The field of Multiple Criteria Decision Making (MCDM) can be said to be both old and new, depending on one's frame of reference. It is old because people have always had to trade off objectives in making decisions. Possibly the first recorded discussion of trade-offs in making decisions and consideration of multiple objectives is the American statesman Benjamin Franklin's way of deciding his position on important decisions. Franklin lived during the 1700s. Many modern researchers have considered MCDM problems. The problem may be represented as an evaluation problem, where the decision maker chooses among a finite set of discrete alternatives; or as a design problem, where the set of decision alternatives is described with a mathematical model. Among the research, the work of Abraham Charnes and William Cooper on goal programming in the late 1950s was a major stimulus to the later explosion of MCDM work. Since then, more than 15,000 papers and numerous books have been written, all of which can be regarded as MCDM contributions from the 1960 s to the present time. Hence MCDM is clearly an important subfield of Management Science or Operations Research, or as a matter of fact, an important field in its own right. The MCDM field has experienced exponential growth in terms of the number of publications as well as the number of citations. The roots of the field are relatively old, extending to research of classical economists and mathematicians. Recent foundations of MCDM were developed in the 1950s and 1960s. The 1970s was an important decade in which many seminal contributions were produced, with the field maturing during the 1980s. MCDM experienced accelerated development during the early 90 s and seems to have continued its 
exponential growth. As an outcome of the growth many subfields have emerged. A recent subfield is Evolutionary Multiobjective Optimization (EMO), in which there have been many active researchers. Interestingly, MCDM has penetrated and continues to penetrate many engineering fields, as well as medicine.

The initials MCDM, of course, stand for Multiple Criteria Decision Making. A paper by Stan Zionts, entitled "MCDM - If not a Roman Numeral, then What?" published in 1979, helped make MCDM an accepted abbreviation for the field.

The book by Saul Gass and Arjang Assad, An Annotated Timeline of Operations Research: An Informal History published in 2005, provided an impetus for writing this book. The Gass-Assad volume explored the timeline of Operations Research, as well as many of its developments. It also includes biographies of many contributors to the field. Though some MCDM contributors and contributions are included in their book, many are not or are just very briefly mentioned. Therefore we thought of producing a book devoted only to MCDM, its contributions and contributors.

We consider MCDM to consist of many subfields, such as Decision Analysis, Goal Programming, work of the "French School," which includes outranking relations, Multiple Objective Mathematical Programming, Fuzzy Set Theory, the Analytic Hierarchy Process (AHP), and Evolutionary Multiobjective Optimization (EMO). We have tried to include all important subfields, contributions, and contributors in compiling this volume. Any omissions are ours, and we apologize in advance for them.

The criteria we used to select contributions and contributors for the volume came from various sources. We used citation statistics from the ISI Web of Science and Google Scholar, a powerful search engine provided under the Google umbrella. We included contributions and contributors we felt were important to the field, well known scholars and their contributions. We were sure to include recipients of our society's (the International Society on Multiple Criteria Decision Making) awards and their main contributions (there have been 34 awards to date - given at meetings of the society).

We decided to organize the book chronologically. We begin with the early history of MCDM, which covers the roots of MCDM through the 
1960s. Then we proceed decade by decade, with one chapter each covering the 1970s, the 1980s, as well as the 1990s and beyond. The impact of recent developments have not yet been fully observed. Therefore, we included the developments in the 2000s together with the 1990s and tried to concentrate on trends observed during that decade. We also mention highlights of the twenty conferences that our society has had. The most recent MCDM conference took place in Chengdu, Sichuan Province, China in June, 2009; the next one is scheduled for Jyväskylä, Finland in June 2011. Each meeting has been unique: we have had conferences in more than a dozen countries around the world. Some have been lavish; others have been less so. Yet each has made its mark in its own way, both in terms of research presented and in terms of the culture of the host area and the hosts.

We did not however, adhere strictly to the chronological order. If a topic is covered only in a certain section, we mention the developments from other decades in that section as well. In some other cases, we decided to discuss topics across different decades to maintain continuity.

We have included brief biographies with pictures of major contributors, which allow for interesting stories and lives to emerge. We obtained help for the biographies and pictures from contributors to the field where possible but used other sources as well. We have also, when possible, included personal aspects of the contributors' lives, emphasizing the human side of the researchers.

One of our inspirations for this book project was Murat Köksalan's presentations in his classes, which summarize major developments in the field together with the pictures of prominent MCDM scholars. We tried to produce a proper mixture of pictures and history.

Why us? Why did we write this book? What are our qualifications for writing such a book? We are all seasoned MCDM scholars, with a collective memory extending back to the 60s. Murat Köksalan, a graduate of the State University of New York (SUNY) Buffalo (under Mark Karwan and Stan Zionts) served many years as a member of the Executive Committee of the International Society on Multiple Criteria Decision Making. He was a past chairperson of the Society's Awards Committee and the chairperson of the organizing committee for the $15^{\text {th }}$ International MCDM Conference held in Ankara, Turkey. He is the 
founding president of the INFORMS Section on MCDM. His research has included problems of Multiple Criteria Decision Making, multiobjective combinatorial optimization, decision support, heuristic search and evolutionary algorithms, among others. He was awarded the Gold Medal of the International Society on Multiple Criteria Decision Making in 2006. Jyrki Wallenius is the current President of the International Society on Multiple Criteria Decision Making. His research has covered problems of Multiple Criteria Decision Making, negotiation analysis, behavioral decision making, decision support, and online auctions. Wallenius is a former editor of the European Journal of Operational Research. He received the Edgeworth-Pareto award from the International Society on Multiple Criteria Decision Making in 1994. Stanley Zionts is Distinguished Professor Emeritus at the State University of New York at Buffalo, where he served on the faculty from 1967 until 2005. He served as Professor of Management at the European Institute for Advanced Studies in Management in Brussels from 1973 to 1975, where Wallenius was his student. Zionts was the founder and first president of the Special Interest Group on MCDM, a predecessor of the International Society on Multiple Criteria Decision Making. Under his leadership the society grew into an international organization with membership of over 1,000 scholars in about 80 different countries. He was the organizer of several international MCDM conferences. His research has included various aspects of linear and integer programming, Multiple Criteria Decision Making, negotiation analysis, decision support, and finance. Zionts was awarded the Gold Medal as well as the Presidential Service Award of the International Society on Multiple Criteria Decision Making in 1992.

Many of the pictures are from the authors' private sources or the contributors themselves. In addition, we have obtained permission to reuse pictures from various sources, including Princeton University, The Archives of the Mathematisches Forschungsinstitut Oberwolfach, and Aalto University School of Economics. Some pictures are in the public domain. Many people have helped us with the compilation of information in this volume. First, we thank the contributors to the field, with whom we have been in contact. In addition, we wish to thank the many other people who have helped us with information or pictures. This 
includes Günter Fandel, Saul Gass, Pekka Korhonen, and Ralph Steuer. Saul Gass deserves a special thank you. Besides furnishing us with several pictures, he provided us with valuable advice regarding the use of pictures.

We have enjoyed preparing and writing this book. It has been both fun and educational. We hope that readers, whether MCDM or related researchers, graduate students, emeritus professors, or just laypersons, enjoy reading the book as much as we have enjoyed writing it. 